\title{
Dramatic Synergy in CoPt Nanocatalysts Stabilized by "Click" Dendrimers for Evolution of Hydrogen from Hydrolysis of Ammonia Borane
}

Qi Wang, ${ }^{\dagger}$ Fangyu Fu, ${ }^{\dagger}$ Sha Yang, ${ }^{\ddagger}$ Marta Martinez Moro, ${ }^{\S}$ Maria de los Angeles Ramirez, ${ }^{\S}$ Sergio Moya, ${ }^{\S 0}$ Lionel Salmon, ${ }^{\| \mathbb{C}}$ Jaime Ruiz, ${ }^{\dagger}$ and Didier Astruc* ${ }^{* \dagger}$

${ }^{\dagger}$ ISM, UMR CNRS N ${ }^{\circ} 5255$, Univ. Bordeaux, 33405 Talence Cedex, France

"Department of Chemistry and Centre for Atomic Engineering of Advanced Materials, Anhui Province Key Laboratory of Chemistry for Inorganic/Organic Hybrid Functionalized Materials, Anhui University, Hefei, Anhui 230601, China

${ }^{\S}$ Soft Matter Nanotechnology Lab, CIC biomaGUNE, Paseo Miramón 182, 20014 Donostia-San Sebastián, Gipuzkoa, Spain

"Laboratoire de Chimie de Coordination, UPR CNRS 8241, 31077 Toulouse Cedex, France

Supporting Information

ABSTRACT: Hydrolysis of ammonia borane $(A B)$ is a very convenient source of $\mathrm{H}_{2}$, but this reaction needs catalytic activation to become practical under ambient conditions. Here this reaction is catalyzed by bimetallic late transition-metal nanoparticles (NPs) that are stabilized and activated by "click" dendrimers. Dendrimers 1 and 2 contain 27 or 81 triethylene glycol terminal groups and 9 or 27 1,2,3-triazole ligands, respectively, located on the dendritic tethers. A remarkable synergy between $\mathrm{Pt}$ and $\mathrm{Co}$ in the $\mathrm{Pt}-\mathrm{Co} /$ “click” dendrimer nanocatalysts is revealed. These $\mathrm{Pt}-\mathrm{Co} /$ "click" dendrimer catalysts are much more efficient for hydrolysis of $\mathrm{AB}$ than either "click" dendrimer-stabilized Co or Pt analogues alone. The best catalyst, $\mathrm{Pt}_{1} \mathrm{Co}_{1} / \mathbf{1}$, stabilized by the nonatriazole "click" dendrimer

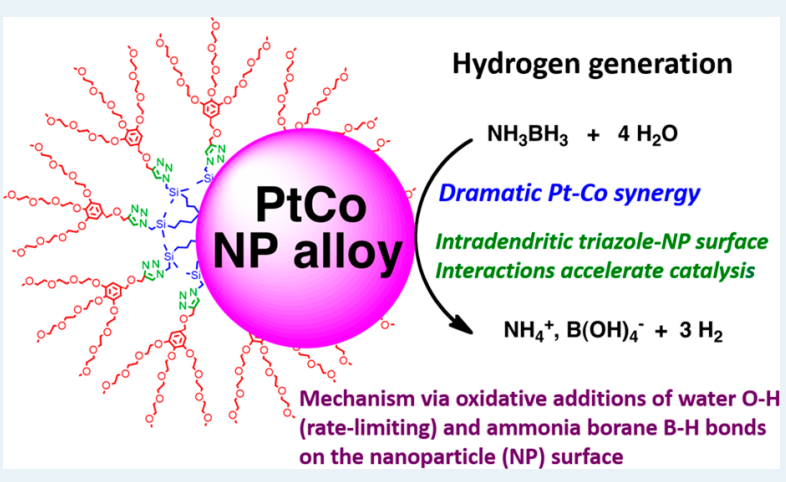
1 achieves a turnover frequency number (TOF) of $303 \mathrm{~mol}_{\mathrm{H}_{2}} \operatorname{mol}_{\mathrm{cat}}{ }^{-1} \mathrm{~min}^{-1}\left(606 \mathrm{~mol}_{\mathrm{H}_{2}} \operatorname{mol}_{\mathrm{Pt}}{ }^{-1} \min ^{-1}\right)$ at $20 \pm 1{ }^{\circ} \mathrm{C}$. The $\mathrm{AB}$ hydrolysis reaction catalyzed by $\mathrm{Pt}_{1} \mathrm{Co}_{1} / \mathbf{1}$ is boosted by NaOH , the TOF value reaching $476.2 \mathrm{~mol}_{\mathrm{H}_{2}} \operatorname{mol}_{\mathrm{cat}^{-1}}^{-1} \mathrm{~min}^{-1}(952.4$ $\mathrm{mol}_{\mathrm{H}_{2}} \mathrm{~mol}_{\mathrm{Pt}}{ }^{-1} \mathrm{~min}^{-1}$ ), one of the very best results ever obtained for this reaction. The presence of $\geq 25 \% \mathrm{Pt}$ in the CoPt nanoalloy provides a reaction rate higher than that obtained with the pure PtNP catalyst alone. The kinetics involves in particular a kinetic isotope effect $k_{\mathrm{D}} / k_{\mathrm{H}}$ of 2.46 obtained for the hydrolysis reaction with $\mathrm{D}_{2} \mathrm{O}$, suggesting that an $\mathrm{O}-\mathrm{H}$ bond of water is cleaved in the rate-determining step. Tandem reactions were carried out for the hydrogenation of styrene with hydrogen generated from the hydrolysis of $\mathrm{AB}$. Performing this tandem reaction with $\mathrm{D}_{2} \mathrm{O}$ shows deuteration of the ethylbenzene products, confirming $\mathrm{O}-\mathrm{D}$ bond cleavage and $\mathrm{H} / \mathrm{D}$ scrambling on the bimetallic NP surface. Finally, a full reaction mechanism is proposed. This dramatic synergy type should also prove to be useful in a number of other catalytic systems.

KEYWORDS: synergy, nanocatalyst, cobalt, dendrimer, hydrolysis, ammonia borane

\section{INTRODUCTION}

Hydrogen energy is considered as the most promising clean energy source in the 21st Century. $\mathrm{H}_{2}$ production upon hydrolysis of ammonia borane $(\mathrm{AB})$ has attracted much attention because of its low molecular weight $\left(30.87 \mathrm{~g} \mathrm{~mol}^{-1}\right)$, high hydrogen content (19.6 wt \%), and high stability in solution. ${ }^{1}$ Duan and Chen recently reported mechanistic studies of the hydrolysis of $\mathrm{AB}$, showing that this reaction fin ally produces $\quad \mathrm{NH}_{4}{ }^{+} \mathrm{B}(\mathrm{OH})_{4}{ }^{-}:{ }^{2}$ $\mathrm{H}_{3} \mathrm{~N} \cdot \mathrm{BH}_{3}+4 \mathrm{H}_{2} \mathrm{O} \rightarrow \mathrm{NH}_{4}^{+} \mathrm{B}(\mathrm{OH})_{4}{ }^{-}+3 \mathrm{H}_{2}$. Intensive efforts have recently been devoted to the investigation of potentially efficient and economical catalysts for $\mathrm{AB}$ hydrol- ysis. ${ }^{3,4}$ Noble-metal nanoparticles (NPs), in particular Pt-based catalysts, have been shown to exhibit high hydrogen evolution rates for this reaction. ${ }^{5}$ Non-noble-metal NP catalysts are by far less efficient than noble-metal NPs, however. ${ }^{6}$ For example, under the same conditions, PtNPs and RhNPs showed efficiencies much higher than those of CoNPs and NiNPs for the hydrolysis of $\mathrm{AB}^{7}$ but the practical use of precious

Received: November 8, 2018

Revised: December 21, 2018

Published: December 24, 2018 
metals in catalysis is limited because of their high cost and global scarcity.

Dendrimers have been extensively used as supports and shown to be highly efficient in catalysis, ${ }^{8}$ including for the encapsulation or stabilization of transition-metal NP catalysts. ${ }^{9}$ Their use to generate hydrogen from hydrogen-rich precursors has been pioneered by Xu's group, ${ }^{10}$ but transition-metal NP catalysts have very rarely been used for this purpose. Only two reports are known, and they deal with monometallic NPs. ${ }^{7,10}$ There has so far been no report of a dendrimer-stabilized bimetallic nanocatalyst for hydrogen generation. Here we report a series of bimetallic NPs with narrow size distributions stabilized by "click" dendrimers ${ }^{11}$ for optimized catalysis of $A B$ hydrolysis using the possible synergy between the two metals. ${ }^{12}$ The two dendrimers, $\mathbf{1}$ and $\mathbf{2}$, that are terminated by triethylene glycol (TEG) with an arene core and contain 27 and 81 TEG tethers are of the zeroth and first generations, respectively (Figure 1). These dendrimers serve as NP stabilizers and activators. The homogeneous bimetallic catalysts are prepared by mixing the two precursor metal salts with one of the dendrimers in water, followed by reduction of the mixture of the transition-metal salts by $\mathrm{NaBH}_{4}$.

These bimetallic nanocatalysts are characterized by transmission electron microscopy (TEM), high-resolution transmission electron microscopy (HRTEM), high-angle annular dark-field scanning transmission electron microscopy (HADDF-STEM), energy dispersive X-ray spectroscopy (EDS), and X-ray photoelectron spectroscopy (XPS). Among these click dendrimer-templated bimetallic NPs, the nanoalloy $\mathrm{Pt}_{1} \mathrm{Co}_{1} / \mathbf{1}$ is shown to be the most active and efficient nanocatalyst for $\mathrm{AB}$ hydrolysis, achieving a turnover frequency number (TOF) of $952.4 \mathrm{~mol}_{\mathrm{H}_{2}} \mathrm{~mol}_{\mathrm{Pt}}{ }^{-1} \mathrm{~min}^{-1}$. The influence of $\mathrm{NaOH}^{13}$ on the reaction efficiency for various bimetallic NPs is investigated. Kinetic isotope effects (KIEs) ${ }^{14}$ using $\mathrm{D}_{2} \mathrm{O}$ instead of $\mathrm{H}_{2} \mathrm{O}$ and tandem reaction for hydrogenation of styrene are also examined in the study of the mechanism of this reaction.

\section{RESULTS AND DISCUSSION}

Synthesis and Characterizations of the $\mathrm{Pt}-\mathrm{Co} / 1$ NPs. "Click" dendrimers 1 and $\mathbf{2}$ were synthesized by following previous reports. ${ }^{11}$ The $\mathrm{Pt}-\mathrm{Co} / \mathbf{1}$ NPs were prepared by mixing dendrimer 1 with two metal salts in water and stirring for 30 min under $\mathrm{N}_{2}$. Then a fresh aqueous solution of sodium borohydride was added, and stirring was continued for $1 \mathrm{~h}$ (Scheme 1 and the Supporting Information).

TEM images were recorded for the $\mathrm{Pt}-\mathrm{Co} / \mathbf{1} \mathrm{NP}$ series, and the average particle sizes were between 1.5 and $2.0 \mathrm{~nm}$ (Figures S3-S5). Very fine and $\mathrm{Pt}_{1} \mathrm{Co}_{1} / \mathbf{1} \mathrm{NPs}$ with a narrow size distribution were indicated by TEM with an average size of $\sim 2 \mathrm{~nm}$ (Figure 2).

A good crystallinity of $\mathrm{Pt}_{1} \mathrm{Co}_{1} / \mathbf{1} \mathrm{NPs}$ was confirmed as shown by the clear lattice fringes in the HRTEM image (Figure $2 \mathrm{a}$, inset). The spacing in the lattice is approximately $2.2 \AA$, if it is assumed that the crystallographic plane of the $\mathrm{Pt}_{1} \mathrm{Co}_{1}$ nanoalloy is $\{111\}$ (JCPDS Card 43-1358). Energy dispersive $\mathrm{X}$-ray spectroscopy (EDS) of the $\mathrm{Pt}_{1} \mathrm{Co}_{1} / \mathbf{1} \mathrm{NPs}$ showed that the $\mathrm{Pt}$ and $\mathrm{Co}$ elements were present in the 011 area (Figure S6), and the alloy structure of $\mathrm{Pt}_{1} \mathrm{Co}_{1} / \mathbf{1}$ NPs was verified by the HAADF elemental mapping spectra (Figure S7). The EDS
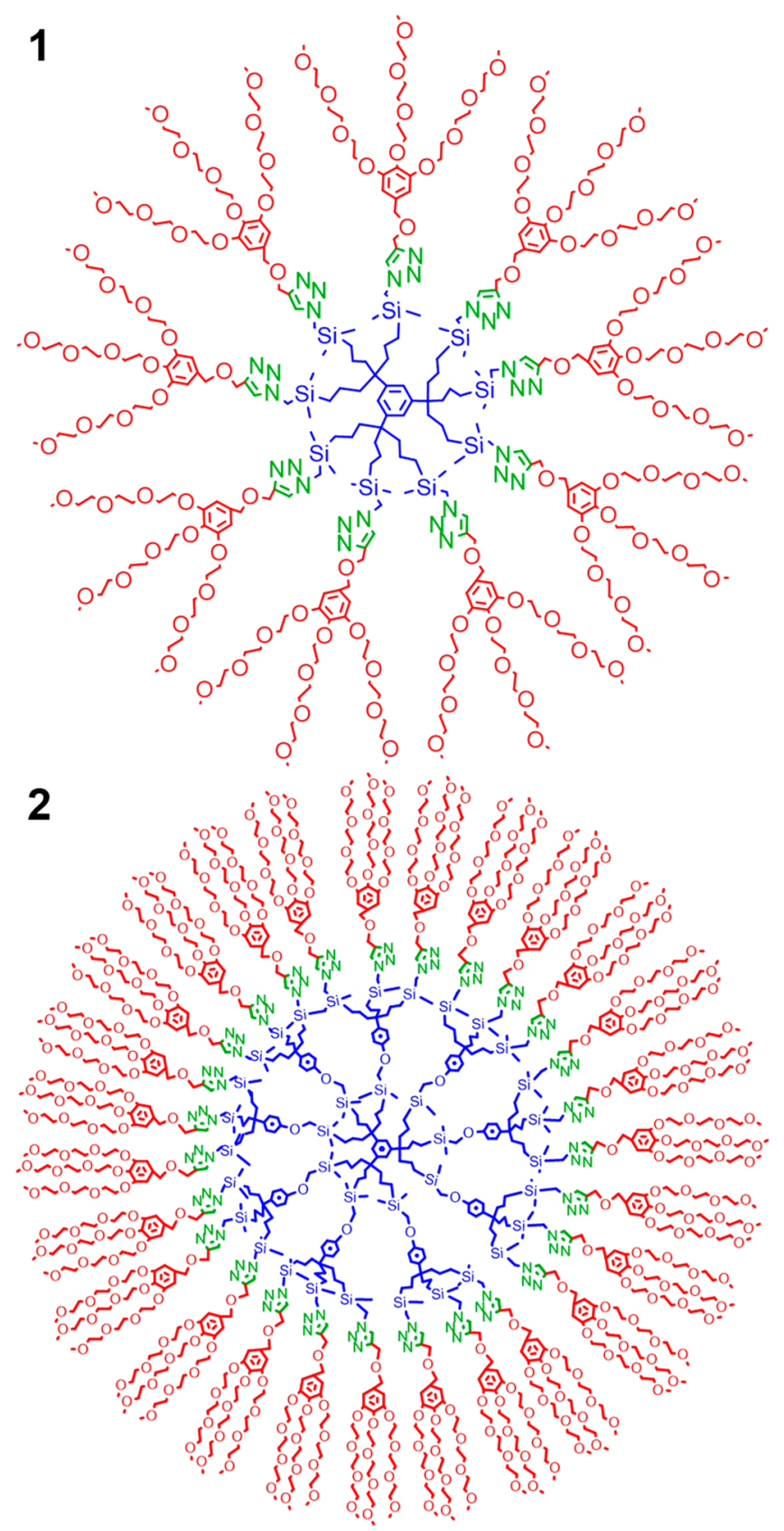

Figure 1. Dendrimer structures 1 and 2.

measurements clearly showed that the alloys did not contain any monometallic NPs.

The X-ray photoelectron spectra of the $\mathrm{Pt}_{1} \mathrm{Co}_{1} / \mathbf{1} \mathrm{NPs}$ showed binding energies of 71.1 and $74.4 \mathrm{eV}$ for $4 \mathrm{f}_{7 / 2}$ and $4 \mathrm{f}_{5 / 2}$, respectively, indicating the presence of metallic $\mathrm{Pt}(0)$ (Figure $3 a)$. In addition, a $778.6 \mathrm{eV}$ binding energy was found for Co $2 \mathrm{p}_{3 / 2}$, showing the existence of $\mathrm{Co}(0)$. Another peak around $782.0 \mathrm{eV}$ demonstrated that there is some $\mathrm{Co}$ (II) species in the $\mathrm{Pt}_{1} \mathrm{Co}_{1} / 1 \mathrm{NP}$ sample, probably due to partial oxidation of $\mathrm{Co}(0)$ just before or during the XPS experiment (Figure $3 \mathrm{~b}$ ). Indeed, catalytic experiments were conducted just after the syntheses and were not subjected to such sample handling. Therefore, it is believed that the $\mathrm{Co}$ (II) species was not present during catalysis. Because the intradendritic triazole ligands are neutral, surface atoms are indeed expected to be $\mathrm{Co}(0)$ and $\operatorname{Pt}(0)$. 
Scheme 1. Synthesis of the Pt-Co/1 NPs
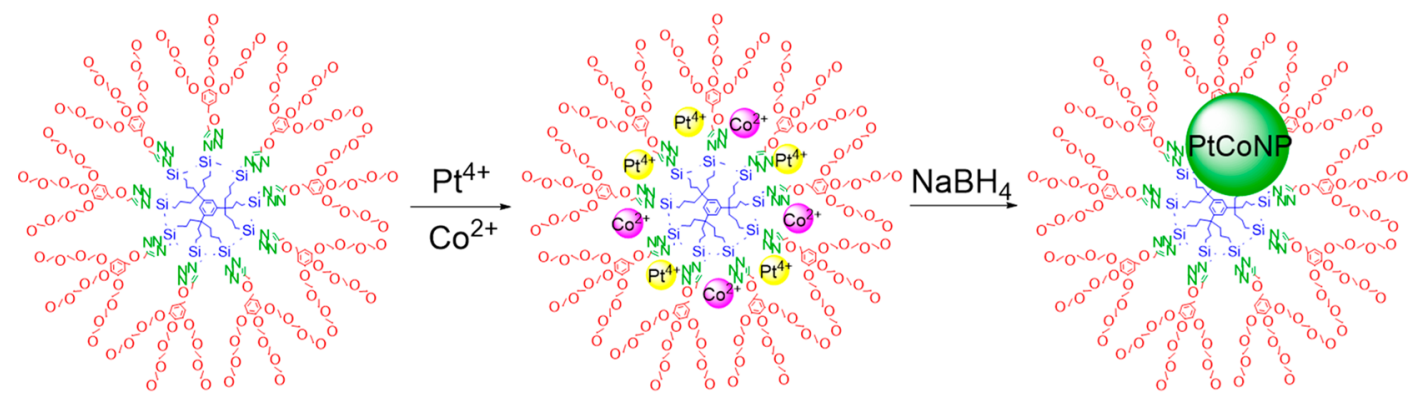

Dendrimer 1

(a)

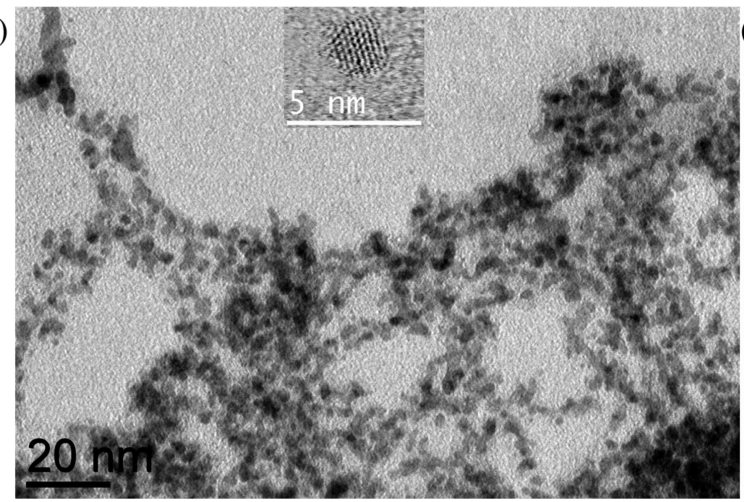

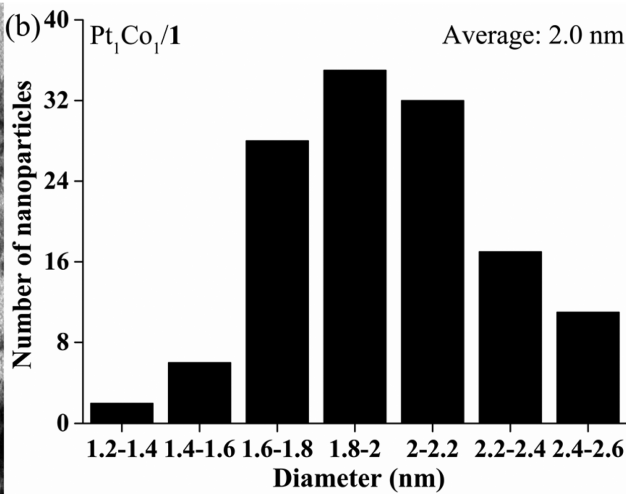

Figure 2. (a) TEM image (inset is the HRTEM image) and (b) size distribution of $\mathrm{Pt}_{1} \mathrm{Co}_{1} / \mathbf{1}$.
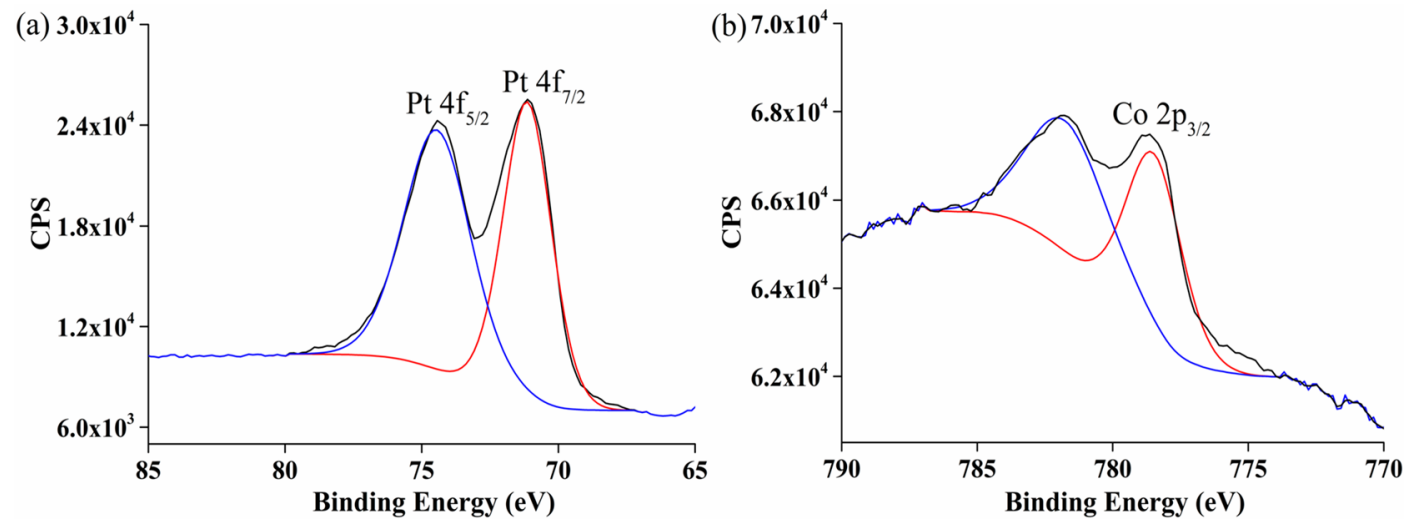

Figure 3. XPS spectra of (a) $\mathrm{Pt} 4 \mathrm{f}$ and (b) Co $2 \mathrm{p}$ in the $\mathrm{Pt}_{1} \mathrm{Co}_{1} / 1$ nanocatalyst. The presence of some Co(II) most probably results from partial oxidation of the sample just before or during the XPS experiment.

Synergistic Catalysis of Ammonia Borane Hydrolysis by Various Pt-Co/1 NPs. The hydrolysis of $\mathrm{AB}$ catalyzed by various $\mathrm{Pt}-\mathrm{Co} / \mathbf{1} \mathrm{NPs}(1 \mathrm{~mol} \%)$ stabilized by dendrimer 1 was carried out at $20 \pm 1{ }^{\circ} \mathrm{C}$ (Table 1 ; see the kinetics in Figure 4). The compositions of the $\mathrm{Pt}-\mathrm{Co} / 1 \mathrm{NPs}$ were adjusted by varying the precursor molar ratios. The term $\mathrm{Pt}-$ Co/1 NPs will be used hereafter for alloys of NPs containing both PtNPs and CoNPs in any proportions in dendrimer 1 . The proportions of the metals in the alloy will be indicated by the numbers following the $\mathrm{Pt}$ and Co symbols (for instance, $\mathrm{Pt}_{1} \mathrm{Co}_{1}$ for equal amounts of $\mathrm{Pt}$ and $\mathrm{Co}$ in the alloy, etc.).

$\mathrm{Pt}$ is known as a very efficient catalyst for the hydrolysis of AB. For example, PtNPs/1 led to a TOF value of $120 \mathrm{~mol}_{\mathrm{H}_{2}}$ $\mathrm{mol}_{\mathrm{cat}}{ }^{-1} \mathrm{~min}^{-1}$. The performance of CoNPs/1, however, was not very good for this reaction, its TOF value being only 8.8 $\operatorname{mol}_{\mathrm{H}_{2}} \operatorname{mol}_{\text {cat }}^{-1} \min ^{-1} .^{7,15}$ Interestingly, when Co was introduced to form a $\mathrm{Pt}-\mathrm{Co}$ alloy $\mathrm{NP}$, catalyst $\mathrm{Pt}_{1} \mathrm{Co}_{1} / 1$ led to a TOF value of $163.6 \mathrm{~mol}_{\mathrm{H}_{2}} \mathrm{~mol}_{\mathrm{cat}}^{-1} \mathrm{~min}^{-1}$ for the hydrolysis of $\mathrm{AB} . \mathrm{Pt}_{1} \mathrm{Co}_{1} / 1$ was the best catalyst among the whole $\mathrm{Pt}-\mathrm{Co} \mathrm{NP}$ series, and the TOF value decreased from its maximum when the Co proportion in the $\mathrm{Pt}-\mathrm{Co}$ alloy was $>1$ / 2. For instance, the TOF value of $\mathrm{Pt}_{1} \mathrm{Co}_{2} / \mathbf{1}$ for this reaction was $150 \mathrm{~mol}_{\mathrm{H}_{2}} \mathrm{~mol}_{\mathrm{cat}}{ }^{-1} \mathrm{~min}^{-1}$. All of the alloyed Pt-Co NPs gave results that were better than those of PtNPs/1 or CoNPs/ 1. In particular, it is remarkable that the introduction of only $25 \%$ of $\mathrm{Pt}$ to the $\mathrm{Pt}-\mathrm{Co}$ alloy led to a nanocatalyst that was better than PtNPs/1 alone (Figure 4). In addition, with a mixture of PtNPs/1 and CoNPs/1 (1:1 Pt:Co ratio) and the total catalyst amount fixed at $1 \%, \mathrm{AB}$ hydrolysis was conducted, and 6 min was needed for complete $\mathrm{H}_{2}$ generation. This is slower than with $1 \% \mathrm{Pt}_{1} \mathrm{Co}_{1} / \mathbf{1} \mathrm{NPs}$ or even than with 
Table 1. Sizes of the Cores and Efficiencies of Various PtCo/1 NP Catalysts at $20 \pm 1^{\circ} \mathrm{C}$ in the Presence or Absence of $0.3 \mathrm{M} \mathrm{NaOH}$

\begin{tabular}{cccc} 
catalyst $^{a}$ & $\begin{array}{c}\text { average } \\
\text { size }(\mathrm{nm})\end{array}$ & $\begin{array}{c}\mathrm{TOF}^{b} \\
\left(\mathrm{~mol}_{\mathrm{H}_{2}} \mathrm{~mol}_{\mathrm{cat}^{-1}} \mathrm{~min}^{-1}\right)\end{array}$ & $\begin{array}{c}\mathrm{TOF} \text { in the presence of } \\
0.3 \mathrm{M} \mathrm{NaOH}\end{array}$ \\
\hline $\mathrm{PtNPs} / \mathbf{1}^{c}$ & 2.3 & 120 & 78.3 \\
$\mathrm{Pt}_{2} \mathrm{Co}_{1} / \mathbf{1}$ & 1.5 & 138.5 & 240 \\
$\mathrm{Pt}_{1} \mathrm{Co}_{1} / \mathbf{1}$ & 2.0 & 163.6 & 257.1 \\
$\mathrm{Pt}_{1} \mathrm{Co}_{2} / \mathbf{1}$ & 1.7 & 150 & 225 \\
$\mathrm{Pt}_{1} \mathrm{Co}_{3} / \mathbf{1}$ & 1.5 & 138.5 & 200 \\
$\mathrm{CoNPs} / \mathbf{1}^{c}$ & 2.2 & 8.8 & 18.8
\end{tabular}

${ }^{a_{T}}$ The $1.0 \mathrm{~mol} \% \mathrm{Pt}-\mathrm{Co} / 1 \mathrm{NPs}$ have been used in the hydrolysis of $\mathrm{AB}$ catalyzed at $20 \pm 1{ }^{\circ} \mathrm{C}$ with an excess $(10 / 1)$ of $\mathrm{NaBH}_{4} \cdot{ }^{b} \mathrm{TOF}=$ $\operatorname{mol}_{\mathrm{H}_{2}}$ released/[ $\operatorname{mol}_{\mathrm{cat}} \times$ reaction time $\left._{(\min )}\right]$ for all atoms (see also Table S1 for TOF by surface atoms). ${ }^{c}$ Experimental results from a previous study. ${ }^{7}$

1\% Pt/1 NPs (Figure S14), demonstrating that there is no synergy with the physical mixture of these CoNPs/1 and PdNPs/ 1.

The catalytic performances of the monometallic nanocatalysts PtNPs/1 and CoNPs/1 toward $\mathrm{AB}$ hydrolysis with $\mathrm{NaOH}$ have been tested. ${ }^{7}$ It was found that $\mathrm{NaOH}$ had a positive influence on the $\mathrm{AB}$ hydrolysis catalyzed by CoNPs/1 but a negative influence on PtNPs/1; therefore, $\mathrm{AB}$ hydrolysis experiments catalyzed by the series of $\mathrm{Pt}-\mathrm{Co} / \mathbf{1} \mathrm{NPs}$ with $\mathrm{NaOH}$ were conducted (Figure 5), and the influence of various quantities of $\mathrm{NaOH}(0.1-0.4 \mathrm{M})$ was further investigated. The results show that the reaction rates were boosted, higher TOF values being obtained for $\mathrm{Pt}-\mathrm{Co} / 1 \mathrm{NPs}$ in the presence of $\mathrm{NaOH}$. The best TOF value of $257.1 \mathrm{~mol}_{\mathrm{H}_{2}} \mathrm{~mol}_{\text {cat }}{ }^{-1} \mathrm{~min}^{-1}$ was reached by $\mathrm{Pt}_{1} \mathrm{Co}_{1} / 1$ with $0.3 \mathrm{M} \mathrm{NaOH}$ (Table S2 and Figure S15), and the TOF value decreased with a higher $\mathrm{NaOH}$ concentration such as $0.4 \mathrm{M}$.

The TOF value of PtNPs/1 decreased from 120 to 78.3 $\operatorname{mol}_{\mathrm{H}_{2}} \operatorname{mol}_{\text {cat }}^{-1} \mathrm{~min}^{-1}$ after the addition of $0.3 \mathrm{M} \mathrm{NaOH}$, but the presence of $\mathrm{NaOH}$ had a positive influence on the $\mathrm{Pt}-\mathrm{Co} /$ 1 NP series. Remarkably, all of the $\mathrm{Pt}-\mathrm{Co} / \mathbf{1} \mathrm{NPs}$ in the various $\mathrm{Co} / \mathrm{Pt}$ proportions tested present very strong synergistic effects between these two metals with $0.3 \mathrm{M}$ $\mathrm{NaOH}$. The synergy culminates in equal amounts of Co and $\mathrm{Pt}$ in the alloy, as in the absence of $\mathrm{NaOH}$, but it is much higher with $\mathrm{NaOH}$ than in its absence in all ratios of Co to Pt (Figure 6).

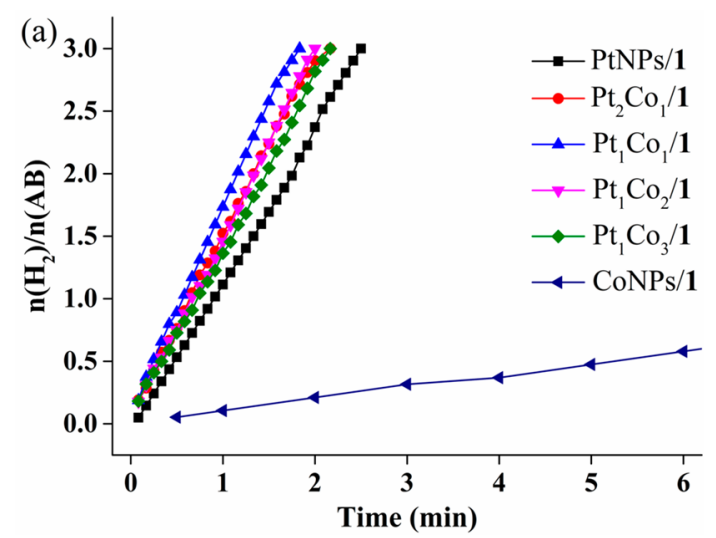

High Selectivity of $\mathrm{Pt}_{1} \mathrm{Co}_{1} / 1$ Compared to Those of Other Bimetallic/1 NPs. A series of "click" dendrimersupported bimetallic NPs of the late transition metals, $\mathrm{Rh}_{1} \mathrm{Co}_{1} /$ 1, $\mathrm{Ru}_{1} \mathrm{Co}_{1} / \mathbf{1}, \mathrm{Pt}_{1} \mathrm{Ni}_{1} / \mathbf{1}$, and $\mathrm{Pt}_{1} \mathrm{Cu}_{1} / \mathbf{1}$, were synthesized using the same method that was used for the syntheses of the $\mathrm{Pt}_{1} \mathrm{Co}_{1} / \mathbf{1}$ nanocatalysts. TEM images have been recorded for these bimetallic NPs (Figures S8-S11). The reactions of AB hydrolysis catalyzed by these bimetallic NPs/1 (1 mol \%) with and without $0.3 \mathrm{M} \mathrm{NaOH}$ have been conducted at $20 \pm 1{ }^{\circ} \mathrm{C}$ (Table 2; see the kinetics in Figure 7).

Furthermore, the $\mathrm{Pt}_{1} \mathrm{Co}_{1}$ NPs stabilized by first-generation dendrimer 2 were synthesized (Figure S12), and the catalytic performances of the $\mathrm{Pt}_{1} \mathrm{Co}_{1} \mathrm{NPs}$ stabilized by two dendrimers were compared for $\mathrm{AB}$ hydrolysis. The $\mathrm{Pt}_{1} \mathrm{Co}_{1} \mathrm{NPs}$ stabilized by dendrimer 1 of the zeroth generation showed results slightly better than those obtained using dendrimer 2 of the first generation. The latter led to a TOF value of $100 \mathrm{~mol}_{\mathrm{H}_{2}} \mathrm{~mol}_{\mathrm{cat}}{ }^{-1}$ $\min ^{-1}$. The dendrimer generation effect ${ }^{8 \mathrm{~b}}$ was found to be weak, probably due to interdendritic and/or NP stabilization.

The comparison showed that $\mathrm{Pt}_{1} \mathrm{Co}_{1} / \mathbf{1}$ exhibited the best efficiency among these bimetallic NP catalysts, followed by the nanocatalysts $\mathrm{Rh}_{1} \mathrm{Co}_{1} / \mathbf{1}$ and $\mathrm{Pt}_{1} \mathrm{Ni}_{1} / \mathbf{1}$. The same TOF value of $94.7 \mathrm{~mol}_{\mathrm{H}_{2}} \mathrm{~mol}_{\mathrm{cat}}{ }^{-1} \mathrm{~min}^{-1}$ has been obtained for the latter two catalysts. The TOF value of PtNPs/1 was $120 \mathrm{~mol}_{\mathrm{H}_{2}} \mathrm{~mol}_{\mathrm{cat}}{ }^{-1}$ $\mathrm{min}^{-1}$, which indicated that there was no synergy between $\mathrm{Pt}$ and Ni. A similar conclusion was reached for $\mathrm{Rh}$ and $\mathrm{Co}$, because the TOF value of RhNPs/1 was $120 \mathrm{~mol}_{\mathrm{H}_{2}} \mathrm{~mol}_{\text {cat }}{ }^{-1}$ $\min ^{-1}$. All of the reactions of hydrolysis of $\mathrm{AB}$ catalyzed by these bimetallic NPs were accelerated with $0.3 \mathrm{M} \mathrm{NaOH}$, as shown by comparison with the results obtained without $\mathrm{NaOH}$ (Figures S16 and S17).

The durability of the best catalyst, $\mathrm{Pt}_{1} \mathrm{Co}_{1} / \mathbf{1}$, has been checked because of its importance for practical applications (Figure 8$)$. Another $\mathrm{AB}$ equivalent $(1 \mathrm{mmol})$ was injected into the flask after the end of a reaction, and the second round was started. The $A B$ hydrolysis reactions have been repeated in this way several times. The results showed that up to the fifth cycle the $\mathrm{Pt}_{1} \mathrm{Co}_{1} / 1$ nanocatalyst still presented a good catalytic property for $\mathrm{AB}$ hydrolysis. After the fifth catalyst recycling, the size of the catalyst was remeasured by TEM, indicating a size increase (Figure S13). It is believed that the NP size increase and agglomeration and concomitant activity decrease in the fifth recycling shown in Figure 8 are due to the accumulation

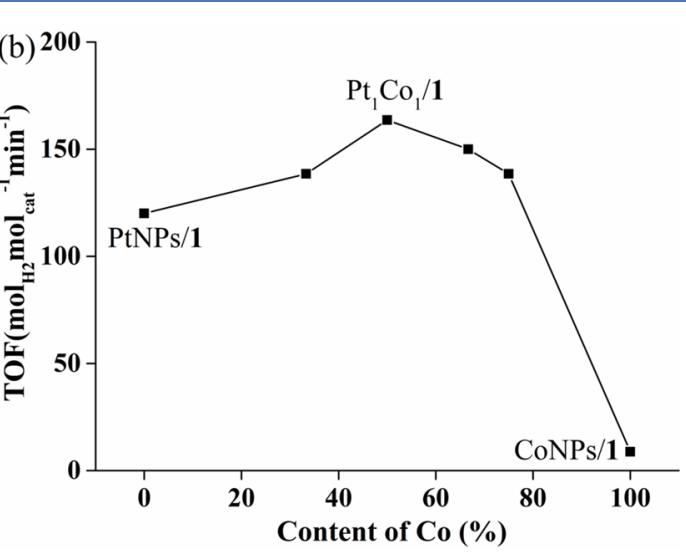

Figure 4. (a) Hydrogen evolution and (b) TOF comparison for $\mathrm{NH}_{3} \mathrm{BH}_{3}$ hydrolysis catalyzed by various $\mathrm{Pt}-\mathrm{Co} / 1$ nanocatalysts at 1 mol \%. 

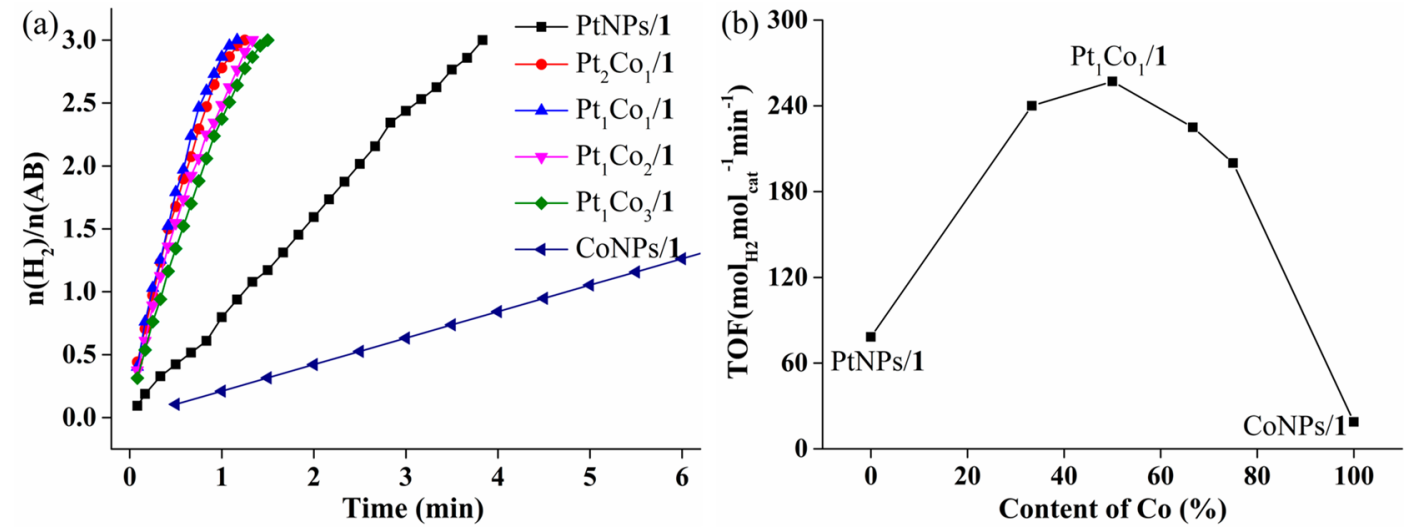

Figure 5. (a) Hydrogen evolution and (b) TOF comparison for $\mathrm{NH}_{3} \mathrm{BH}_{3}$ hydrolysis catalyzed by various $\mathrm{Pt}-\mathrm{Co} / \mathbf{1}$ nanocatalysts (1 mol \%) in the presence of $0.3 \mathrm{M} \mathrm{NaOH}$.

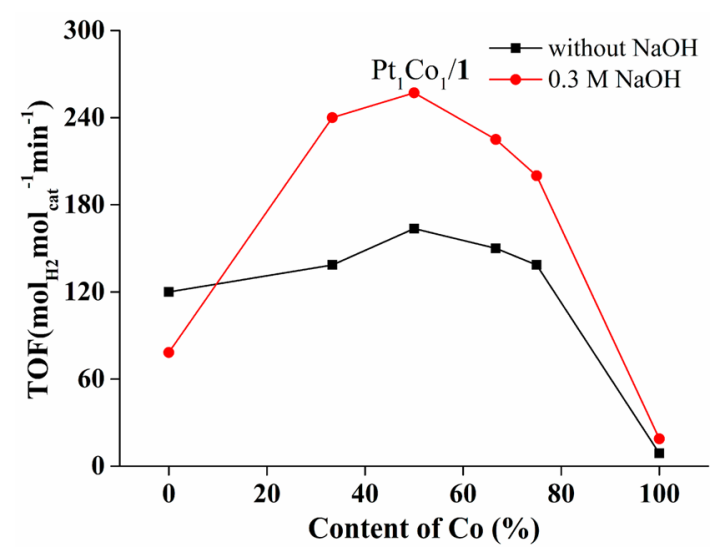

Figure 6. TOF comparison of $\mathrm{NH}_{3} \mathrm{BH}_{3}$ hydrolysis catalyzed by various $\mathrm{Pt}-\mathrm{Co} / 1$ nanocatalysts $(1 \mathrm{~mol} \%)$ with and without $0.3 \mathrm{M}$ $\mathrm{NaOH}$.

Table 2. Sizes of the Cores and Efficiencies of Bimetallic $\mathrm{NPs} / 1$ Catalysts with and without $0.3 \mathrm{M} \mathrm{NaOH}$ at $20 \pm 1$ ${ }^{\circ} \mathrm{C}$

\begin{tabular}{lccc}
\multicolumn{1}{c}{$\begin{array}{c}\text { average } \\
\text { size } \\
\text { catalyst }\end{array}$} & $\begin{array}{c}{ }^{a} \\
(\mathrm{~nm})\end{array}$ & $\begin{array}{c}\mathrm{TOF}^{b} \\
\left(\mathrm{~mol}_{\mathrm{H}_{2}} \mathrm{~mol}_{\mathrm{cat}^{-1}} \mathrm{~min}^{-1}\right)\end{array}$ & $\begin{array}{c}\mathrm{TOF} \text { with } 0.3 \mathrm{M} \mathrm{NaOH} \\
\left(\mathrm{mol}_{\mathrm{H}_{2}} \mathrm{~mol}_{\mathrm{cat}^{-1}} \mathrm{~min}^{-1}\right)\end{array}$ \\
$\mathrm{Pt}_{1} \mathrm{Co}_{1} / \mathbf{1}$ & 2.0 & 163.6 & 257.1 \\
$\mathrm{Rh}_{1} \mathrm{Co}_{1} / \mathbf{1}$ & 1.8 & 94.7 & 200 \\
$\mathrm{Ru}_{1} \mathrm{Co}_{1} / \mathbf{1}$ & 2.1 & 33.3 & 64.3 \\
$\mathrm{Pt}_{1} \mathrm{Ni}_{1} / \mathbf{1}$ & 1.8 & 94.7 & 133.3 \\
$\mathrm{Pt}_{1} \mathrm{Cu}_{1} / \mathbf{1}$ & 1.8 & 12 & 17.6 \\
$\mathrm{Pt}_{1} \mathrm{Co}_{1} / \mathbf{2}$ & 2.0 & 100 & 163.6
\end{tabular}

${ }^{a}$ The $1.0 \mathrm{~mol} \%$ bimetallic NPs were utilized in the catalysis of $\mathrm{AB}$ hydrolysis with an excess of $\mathrm{NaBH}_{4}(10 / 1)$ at $20 \pm 1{ }^{\circ} \mathrm{C}$. ${ }^{b} \mathrm{TOF}=$ $\mathrm{mol}_{\mathrm{H}_{2}}$ released/ $\left[\mathrm{mol}_{\text {cat }} \times\right.$ reaction time $\left._{(\min )}\right]$ for all atoms (see also Table S3 for TOF related to surface atoms).

of the sodium and ammonium products of the reaction adsorbed on the NP surface.

Mechanistic Studies of the AB Hydrolysis Reaction Catalyzed by $\mathrm{Pt}_{1} \mathrm{Co}_{1} / 1$. The determination of the second Damköhler number $\left(\mathrm{Da}_{\mathrm{II}}=0.02\right)$, much lower than unity, allowed us to rule out mass-transfer-induced diffusion control (see the Supporting Information). The slope of the logarithmic plot of hydrogen generation versus $\mathrm{Pt}_{1} \mathrm{Co}_{1} / \mathbf{1}$ concentration is
1.16 (Figure 9), which shows that the reaction is first order in the concentration of the catalyst.

The $A B$ hydrolysis reaction is zero order in the concentration of $\mathrm{AB}$ (the slope of the logarithmic plot of hydrogen generation vs $\mathrm{AB}$ concentration is a nearly horizontal line; slope of 0.09 in Figure 10), which rules out activation of $\mathrm{AB}$ alone as the rate-determining step.

The time dependence measurement of hydrogen generation at various temperatures has led to the determination of a low activation energy $\left(E_{\mathrm{a}}=28.8 \mathrm{~kJ} \mathrm{~mol}^{-1}\right.$ for $\mathrm{Pt}_{1} \mathrm{Co}_{1} / \mathbf{1}$; Figure 11 and calculation in the Supporting Information).

The isotopic experiment using $\mathrm{D}_{2} \mathrm{O}$ instead of $\mathrm{H}_{2} \mathrm{O}$ was conducted for the $\mathrm{Pt}_{1} \mathrm{Co}_{1} / \mathbf{1}$-catalyzed $\mathrm{AB}$ hydrolysis, and the kinetic results are presented in Figure 12, showing a kinetic isotope effect (KIE) of 2.46. The kinetic studies, and in particular the latter experiment, suggest that the water $\mathrm{O}-\mathrm{H}$ bond is cleaved in the rate-determining step.

In conclusion, the results obtained here show a strong and remarkable bimetallic synergy between cobalt and platinum optimized in the $\mathrm{Co}_{1} \mathrm{Pt}_{1}$ alloy, in particular with $0.3 \mathrm{M} \mathrm{NaOH}$. This synergy also involves the "click" dendrimer supports, in particular the intradendritic 1,2,3-triazole ligands that have proven to be essential. ${ }^{9 \mathrm{~g}, 11 \mathrm{c}, 16}$ Previously, the coordination of various transition-metal NPs to the triazole ligands of the same dendrimer 1 near the periphery of the dendrimer has been shown to be highly beneficial for NP catalysis. This has been demonstrated in very efficient catalysis by $\mathrm{PdNP} / \mathbf{1}$ with parts per million Pd levels for various carbon-carbon cross coupling reactions (Miyaura-Suzuki, Sonogashira, and Heck), ${ }^{11 \mathrm{c}, 16 \mathrm{~b}, \mathrm{~d}}$ by CuNP/1 for "click" reactions, ${ }^{9 g, 16 e}$ and by a variety of transition-metal NPs/1 for nitrophenol reduction. ${ }^{16 f, g}$ Altogether, these "click" dendrimers 1 and 2, i.e., containing the intradendritic 1,2,3-triazole ligands, have been shown to boost catalysis of various reactions by molecular, ionic, and NP catalysts. The electronic donicity of the triazole ligand with respect to the NP surfaces is responsible for the superior catalytic activity of these NP surfaces, ${ }^{16 e}$ in particular here for the difficult oxidative addition in the rate-determining step of an $\mathrm{O}-\mathrm{H}$ bond of water. Note that the fully stable "click" dendrimers $\mathbf{1}$ and $\mathbf{2}$ are also used in catalytic amounts and recovered unchanged in the aqueous phase at the end of the reactions. These results are among the very best obtained compared to results for related bimetallic nanocatalysts in the literature as shown in the comparative Table S4. 

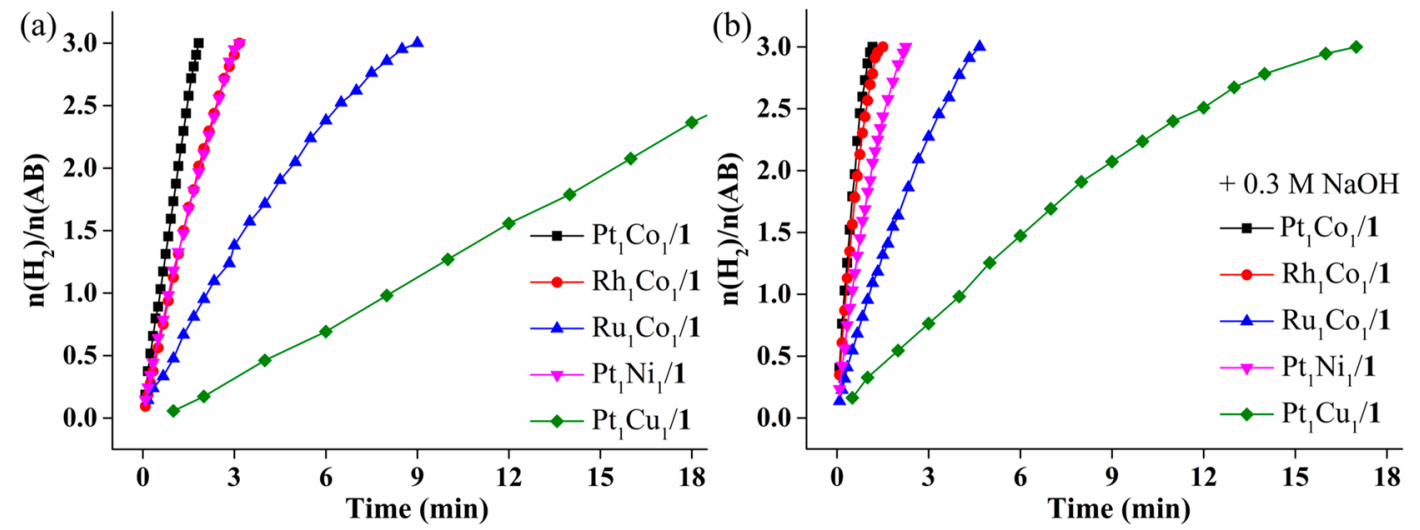

Figure 7. Comparison of the evolution of $\mathrm{H}_{2}$ upon reaction between $\mathrm{NH}_{3} \mathrm{BH}_{3}$ and $\mathrm{H}_{2} \mathrm{O}$ catalyzed by 1 mol $\%$ bimetallic NPs/1 (a) without $\mathrm{NaOH}$ and (b) with $0.3 \mathrm{M} \mathrm{NaOH}$.

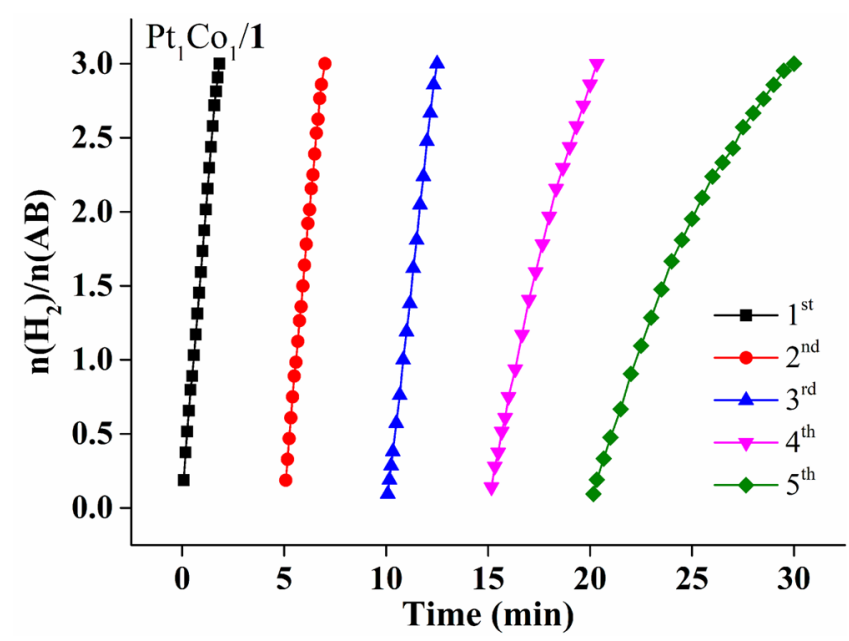

Figure 8. Plots of the volume of hydrogen vs time for $\mathrm{AB}$ hydrolysis catalyzed by $1 \mathrm{~mol} \% \mathrm{Pt}_{1} \mathrm{Co}_{1} / \mathbf{1}$ during the tests of reusability.

The practical usages of hydrogen produced in the $A B$ hydrolysis reaction are not only hydrogen storage but also its direct use in situ, for tandem reactions, and for mechanistic studies of the $\mathrm{AB}$ hydrolysis reaction. Examples of the latter applications are shown here. Tandem reactions were carried out for the hydrogenation of styrene with hydrogen generated from $\mathrm{AB}$ hydrolysis with $\mathrm{D}_{2} \mathrm{O}$. In a sealed system consisting of two communicating chambers (Figure S18), the hydrogen was produced from $\mathrm{AB}$ hydrolysis with $\mathrm{D}_{2} \mathrm{O}$, the reaction being catalyzed by $\mathrm{Pt}_{1} \mathrm{Co}_{1} / \mathbf{1}$ in the left tube. This hydrogen is used for the hydrogenation ${ }^{17}$ of styrene catalyzed by $\mathrm{Ni}_{2} \mathrm{Pt} @ Z \mathrm{ZIF}-8^{18}$ in the right tube (Figure 13; see details in the Supporting Information). The reaction mixture of styrene hydrogenation was stirred at $50{ }^{\circ} \mathrm{C}$ for $12 \mathrm{~h}$, and then the ${ }^{1} \mathrm{H}$ NMR and GC mass spectra of the hydrogenation product were recorded. The integration of the ${ }^{1} \mathrm{H}$ NMR peak around 1.2 and $2.6 \mathrm{ppm}$ showed a reduced intensity compared to that of ethylbenzene in its ${ }^{1} \mathrm{H}$ NMR spectrum (Figure S19). Three peaks around 106, 107, and $108 \mathrm{ppm}$ were found in the mass spectrum (Figure S20), showing that there were three hydrogenation products of styrene, which contained zero, one, and two D atoms, respectively, in the ethyl substituent.

Several mechanisms have been proposed for the late transition-metal NP-catalyzed $\mathrm{AB}$ hydrolysis. $\mathrm{Xu}$ et al. proposed an attack of water on an activated complex provoking cleavage of the $\mathrm{B}-\mathrm{N}$ bond and hydrolysis of $\mathrm{NH}_{3}$ generating hydrogen. ${ }^{3}$ Jagirdar's group proposed attack of water on a transient $\mathrm{M}-\mathrm{H}$ bond by analogy with the hydrolysis of $\mathrm{BH}_{4}{ }^{-19}$ $\mathrm{Na}$ and $\mathrm{Ma}$ proposed a similar mechanism related to the hydrolysis of $\mathrm{BH}_{4}^{-20} \cdot{ }^{20} \mathrm{Fu}$ suggested $\mathrm{BH}_{3} \mathrm{OH}^{-} \mathrm{NH}_{4}^{+}$formation and attack of water to generate hydrogen. ${ }^{21} \mathrm{Chen}^{2}$ and $\mathrm{Fu}^{18}$ suggested $\mathrm{O}-\mathrm{H}$ bond cleavage in the water molecule in the rate-determining step.
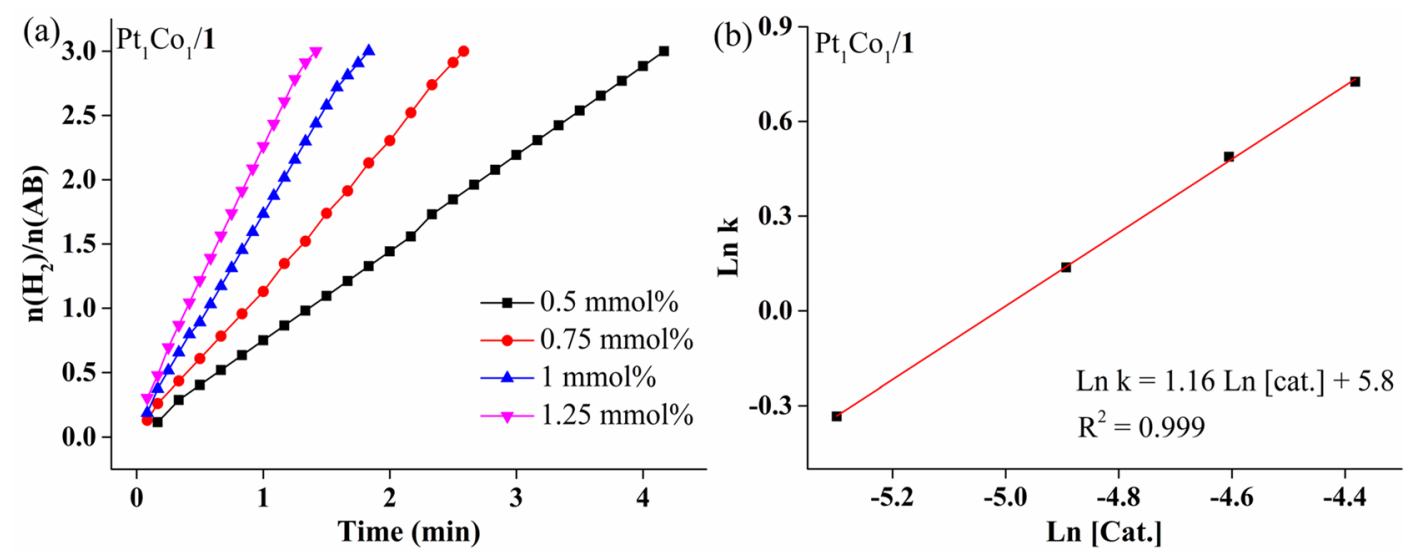

Figure 9. (a) Plots of the times of the catalyzed $\mathrm{AB}$ hydrolytic dehydrogenation catalyzed by the $\mathrm{Pt}_{1} \mathrm{Co}_{1} / \mathbf{1}$ nanocatalyst with various catalyst amounts. (b) Plots of the rates of $\mathrm{H}_{2}$ generation vs the concentration of the $\mathrm{Pt}_{1} \mathrm{Co}_{1} / 1$ nanocatalyst both on natural logarithmic scales. 

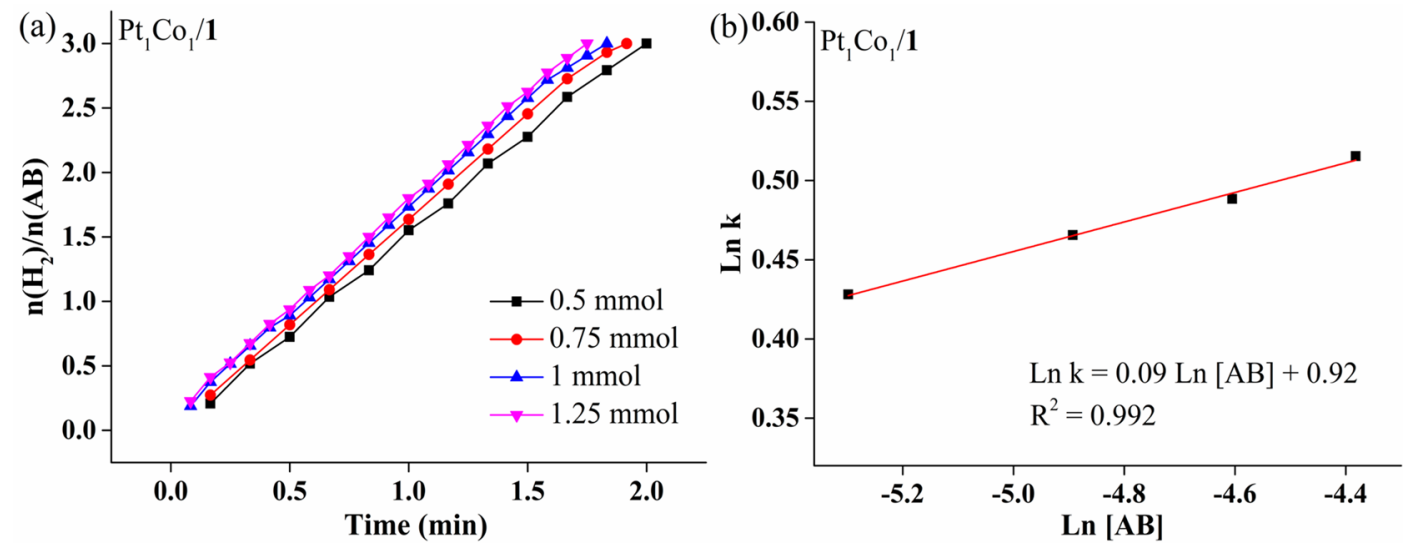

Figure 10. (a) Plots of the volume of hydrogen generated vs time for the hydrolysis of AB catalyzed by $1 \mathrm{~mol} \% \mathrm{Pt}_{1} \mathrm{Co}_{1} / \mathbf{1}$ nanocatalyst. (b) Plots of the $\mathrm{H}_{2}$ generation rate vs $\mathrm{AB}$ concentration both on natural logarithmic scales.
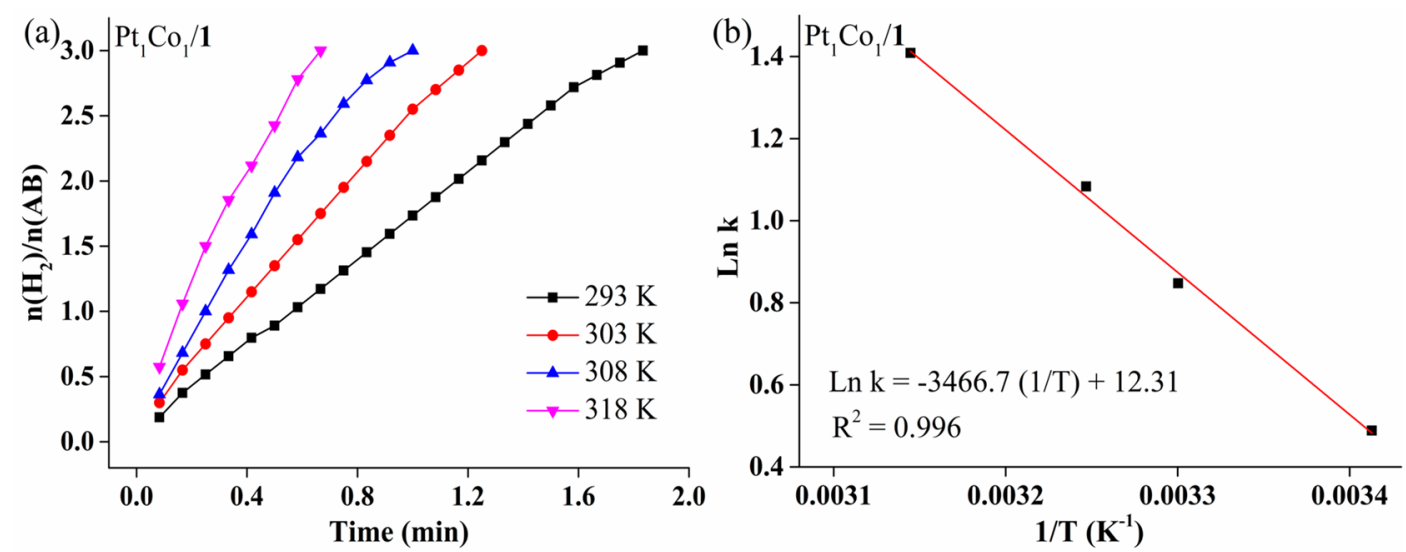

Figure 11. (a) Plots of the hydrogen volume vs time for $\mathrm{AB}$ hydrolysis catalyzed at various temperatures by $1 \mathrm{~mol}^{\%} \mathrm{Pt}_{1} \mathrm{Co}_{1} / \mathbf{1} \mathrm{catalyst}$ (b) Kinetic data obtained from the Arrhenius plots.

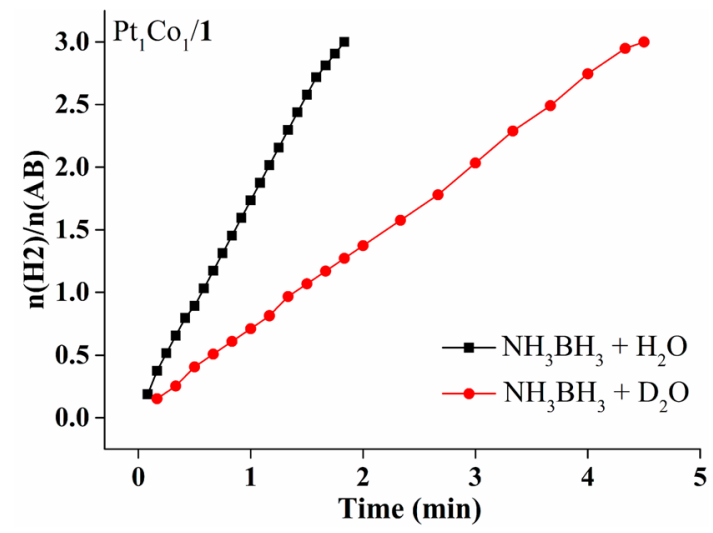

Figure 12. Evolution of $\mathrm{H}_{2}$ upon $\mathrm{NH}_{3} \mathrm{BH}_{3}$ hydrolysis with $\mathrm{H}_{2} \mathrm{O}$ and $\mathrm{D}_{2} \mathrm{O}$ catalyzed by $1 \mathrm{~mol} \%$ nanocatalyst $\mathrm{Pt}_{1} \mathrm{Co}_{1} / \mathbf{1}(\mathrm{KIE}=2.46)$.

A mechanistic proposal based on our experimental results follows. $\left[\mathrm{H}_{3} \mathrm{NBH}_{2} \mathrm{H}\right] \cdots \mathrm{H}-\mathrm{OH}$ hydrogen bonding resulting from the hydridic property of the $\mathrm{B}-\mathrm{H}$ bond is suggested here to play a key role. A hydridic $\mathrm{BH}$ is proposed to transfer its $\mathrm{H}$ atom to the NP surface, which formally corresponds to an oxidative addition of this $\mathrm{B}-\mathrm{H}$ bond to the surface. Oxidative addition of the water $\mathrm{O}-\mathrm{H}$ bond proceeds in the ratedetermining step, as essentially indicated from the large KIE $\left(k_{\mathrm{H}} / k_{\mathrm{D}}=2.46\right)$ with $\mathrm{D}_{2} \mathrm{O}$. The favorable $\mathrm{OH}^{-}$effect for bimetallic NPs/ 1 is in accord with coordination of $\mathrm{OH}^{-}$to the

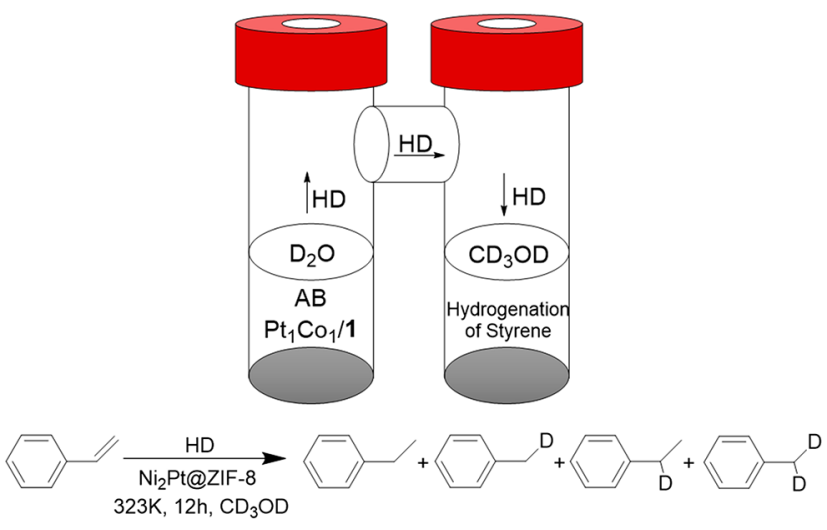

Figure 13. Tandem reaction for hydrogenation with "HD" generated from $\mathrm{AB}$ hydrolysis catalyzed by $\mathrm{Pt}_{1} \mathrm{Co}_{1} / \mathbf{1}$. On the arrow, "HD" represents a mixture of $\mathrm{H}_{2}, \mathrm{HD}$, and $\mathrm{D}_{2}$ (see the text).

NP surface, which makes the NP more electron-rich and beneficial to the oxidative addition of $\mathrm{H}_{2} \mathrm{O}$. On the contrary, $\mathrm{OH}^{-}$has a negative effect on $\mathrm{AB}$ hydrolysis catalyzed by PtNPs/1, probably because $\mathrm{H}$-bonding between $\mathrm{H}_{2} \mathrm{O}$ and $\mathrm{AB}$ is sufficient to enhance $\mathrm{O}-\mathrm{H}$ oxidative addition by the most electron-rich PtNP surface. Accordingly, there is no need at this point to further enrich the electron density of the monometallic PtNP surface by $\mathrm{OH}^{-}$coordination. Furthermore, the added $\mathrm{OH}^{-}$would partly occupy the surface active 
sites of PtNPs, inhibiting the oxidative addition of the $\mathrm{O}-\mathrm{H}$ bond of water, thereby decelerating the reaction. In this step, synergy between a Pt atom and a Co is likely to be at play. The more electron-rich PtNP atoms would most probably form both $\mathrm{Pt}-\mathrm{H}$ bonds due to the high strength of the $\mathrm{Pt}-\mathrm{H}$ bonds, while the less electron-rich Co atom would bind the electronrich $\mathrm{OH}$ group to form a $\mathrm{Co}-\mathrm{OH}$ bond. The dihydride-NP species would then easily form $\mathrm{H}_{2}$ by reductive elimination as is well-known in transition-metal organometallic chemistry and catalysis. ${ }^{22}$ The tandem reaction with $\mathrm{D}_{2} \mathrm{O}$ showing deuteration of the ethylbenzene products confirms $\mathrm{H} / \mathrm{D}$ exchange after $\mathrm{O}-\mathrm{D}$ cleavage and $\mathrm{H} / \mathrm{D}$ scrambling on the NP surface before reductive elimination. Given the KIE value and the favorable effect of $\mathrm{OH}^{-}$on the reaction rate, it is not possible that protonation of $\mathrm{AB}$ by water (heterolytic $\mathrm{H}_{2} \mathrm{O}$ or $\mathrm{D}_{2} \mathrm{O}$ cleavage) proceeds before the rate-limiting step. A tentative reaction mechanism is represented in Scheme 2. Reductive

Scheme 2. Suggested Mechanism for the AB Hydrolysis Reaction Catalyzed by $\mathrm{Pt}_{1} \mathrm{Co}_{1} / 1$

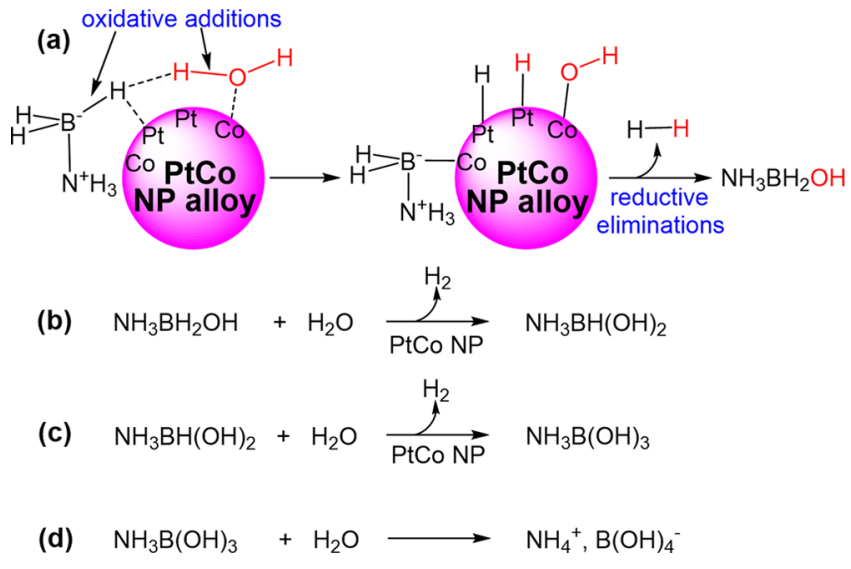

elimination of $\mathrm{H}_{2}$ is accompanied by reductive elimination of the two fragments, $\mathrm{NH}_{3} \mathrm{BH}_{2}-$ and $\mathrm{OH}$-, to form the $\mathrm{NH}_{3} \mathrm{BH}_{2} \mathrm{OH}$ hydroxy intermediate. This first overall step (a) thus corresponds to the substitution in ammonia borane of an $\mathrm{H}$ atom by $\mathrm{OH}$ on boron. Each of the two subsequent $\mathrm{H}_{2}$ evolution steps ( $b$ and $c$ ) is proposed to proceed by the same mechanism leading to adsorbed $\mathrm{B}(\mathrm{OH})_{3} \mathrm{NH}_{3}$ that upon hydrolysis produces $\mathrm{NH}_{4}{ }^{+} \mathrm{B}(\mathrm{OH})_{4}{ }^{-}(\mathrm{d})$.

\section{CONCLUDING REMARKS}

In conclusion, two generations of "click" dendrimers stabilized various bimetallic NPs that catalyze $A B$ hydrolysis producing 3 mol of hydrogen. The reaction order in $A B$ is zero and in the NP catalyst is one. A remarkably highly positive synergistic effect is discovered for the $\mathrm{Pt}-\mathrm{Co} / 1$ nanocatalysts containing various proportions of $\mathrm{Co}$ and PtNPs in the nanoalloys, so that the presence of even down to $25 \% \mathrm{Pt}$ in the $\mathrm{Pt}-\mathrm{Co} / 1$ nanocatalyst produces a catalyst that is more efficient than $\mathrm{PtNP} / \mathrm{1}$. NaOH increases the reaction rate, except for that of PtNPs. The maximum synergistic effect is disclosed both with and without $0.3 \mathrm{M} \mathrm{NaOH}$ with nanoalloys containing equal amounts of $\mathrm{Co}$ and Pt. This dramatic synergy between Pt and Co is highly selective compared to that of other bimetallic NPs stabilized by the dendrimer 1 . With other supports, these PtCo nanoalloys are on the contrary less efficient. Thus, the synergy also involves the dendrimer, in particular its intradendritic 1,2,3-triazole ligands that activate the NP surface. The TOF value reached with $\mathrm{Pt}_{1} \mathrm{Co}_{1} / 1$ is $476.2 \mathrm{~mol}_{\mathrm{H}_{2}} \mathrm{~mol}_{\text {cat }}{ }^{-1} \mathrm{~min}^{-1}$ (952.4 $\mathrm{mol}_{\mathrm{H}_{2}} \mathrm{~mol}_{\mathrm{Pt}}{ }^{-1} \mathrm{~min}^{-1}$ ) for the production of $3 \mathrm{~mol}$ of hydrogen completed in $70 \mathrm{~s}$ at $20{ }^{\circ} \mathrm{C}$ (Table S1), one of the best results ever recorded. The kinetic isotope effect $\left(k_{\mathrm{H}} / k_{\mathrm{D}}=\right.$ 2.46) with $\mathrm{D}_{2} \mathrm{O}$ indicates that the cleavage of the water $\mathrm{O}-\mathrm{H}$ bond proceeds as the rate-determining step facilitated by hydrogen bonding between a $\mathrm{B}-\mathrm{H}$ bond of $\mathrm{AB}$ and a $\mathrm{H}$ atom of water. This mechanism is suggested to also involve another oxidative addition, that of a hydridic $\mathrm{B}-\mathrm{H}$ bond of $\mathrm{AB}$. This is followed by reductive eliminations of both $\mathrm{H}_{2}$ and $\mathrm{NH}_{3} \mathrm{BH}_{2} \mathrm{OH}$ and two analogous overall steps before hydrolysis to $\mathrm{NH}_{4}{ }^{+} \mathrm{B}(\mathrm{OH})_{4}{ }^{-}$. The tandem reaction with $\mathrm{D}_{2} \mathrm{O}$ that involves $\mathrm{AB}$ hydrolysis and styrene hydrogenation producing deuterated ethylbenzenes confirms $\mathrm{O}-\mathrm{D}$ bond cleavage as the rate-limiting step and H/D scrambling on the NP surface before reductive elimination of $\mathrm{HD}, \mathrm{H}_{2}$, and $\mathrm{D}_{2}$.

\section{ASSOCIATED CONTENT}

\section{Supporting Information}

The Supporting Information is available free of charge on the ACS Publications website at DOI: 10.1021/acscatal.8b04498.

General data, experimental details, characterizations, and kinetics of $\mathrm{AB}$ hydrolysis (PDF)

\section{AUTHOR INFORMATION}

\section{Corresponding Author}

*E-mail: didier.astruc@u-bordeaux.fr.

ORCID 웅

Sergio Moya: 0000-0002-7174-1960

Lionel Salmon: 0000-0002-8064-8960

Didier Astruc: 0000-0001-6446-8751

\section{Notes}

The authors declare no competing financial interest.

\section{ACKNOWLEDGMENTS}

Financial support from the China Scholarship Council (CSC) of the People's Republic of China (grants to Q.W. and F.F.), the Centre National de la Recherche Scientifique (CNRS), the University of Bordeaux, and CIC biomaGUNE at San Sebastian is gratefully acknowledged.

\section{REFERENCES}

(1) (a) Staubitz, A.; Robertson, A. P. M.; Manners, I. AmmoniaBorane and Related Compounds as Dihydrogen Sources. Chem. Rev. 2010, 110, 4079-4124. (b) Rossin, A.; Peruzzini, M. AmmoniaBorane and Amine-Borane Dehydrogenation Mediated by Complex Metal Hydrides. Chem. Rev. 2016, 116, 8848-8872.

(2) Chen, W.; Li, D.; Wang, Z.; Qian, G.; Sui, Z.; Duan, X.; Zhou, X.; Yeboah, I.; Chen, D. Reaction mechanism and kinetics for hydrolytic dehydrogenation of ammonia borane on a Pt/CNT catalyst. AIChE J. 2017, 63, 60-65.

(3) For a seminal report, see: Xu, Q; Chandra, M. Catalytic activities of non-noble metals for hydrogen generation from aqueous ammonia-borane at room temperature. J. Power Sources 2006, 163, 364-370.

(4) Reviews: (a) Hamilton, C. W.; Baker, R. T.; Staubitz, A.; Manners, I. B-N compounds for chemical hydrogen storage. Chem. Soc. Rev. 2009, 38, 279-293. (b) Zhu, Q.-L.; Xu, Q. Liquid organic and inorganic chemical hydrides for high-capacity hydrogen storage. Energy Environ. Sci. 2015, 8, 478-512. (c) Zhan, W.-W.; Zhu, Q.-L.; $\mathrm{Xu}, \mathrm{Q}$. Dehydrogenation of Ammonia Borane by Metal Nanoparticle Catalysts. ACS Catal. 2016, 6, 6892-6905. (d) Akbayrak, S.; Özkar, S. 
Ammonia borane as hydrogen storage materials. Int. J. Hydrogen Energy 2018, 43, 18592-18606.

(5) (a) Lee, J.; Farha, O. K.; Roberts, J.; Scheidt, K. A.; Nguyen, S. T.; Hupp, J. T. Metal-organic framework materials as catalysts. Chem. Soc. Rev. 2009, 38, 1450-1459. (b) Farrusseng, D.; Aguado, S.; Pinel, C. Metal-organic frameworks: opportunities for catalysis. Angew. Chem., Int. Ed. 2009, 48, 7502-7513. (c) Rakap, M.; Ozkar, S. Hydrogen generation from the hydrolysis of ammonia-borane using intrazeolite cobalt(0) nanoclusters catalyst. Int. J. Hydrogen Energy 2010, 35, 3341-3346. (d) Dhakshinamoorthy, A.; Garcia, H. Catalysis by metal nanoparticles embedded on metal-organic frameworks. Chem. Soc. Rev. 2012, 41, 5262-5284. (e) Liu, J.; Chen, L.; Cui, H.; Zhang, J.; Zhang, L.; Su, C. Y. Applications of metal-organic frameworks in heterogeneous supramolecular catalysis. Chem. Soc. Rev. 2014, 43, 6011-6061. (f) Chughtai, A. H.; Ahmad, N.; Younus, H. A.; Laypkov, A.; Verpoort, F. Metal-organic frameworks: versatile heterogeneous catalysts for efficient catalytic organic transformations. Chem. Soc. Rev. 2015, 44, 6804-6849. (g) Zeng, L.; Guo, X.; He, C.; Duan, C. Metal-Organic Frameworks: Versatile Materials for Heterogeneous Photocatalysis. ACS Catal. 2016, 6, 7935-7947.

(6) (a) Xu, Q.; Chandra, M. A. Portable hydrogen generation system: Catalytic hydrolysis of ammonia-borane. J. Alloys Compd. 2007, 446, 729-732. (b) Aijaz, A.; Karkamkar, A.; Choi, Y. J.; Tsumori, N.; Rönnebro, E.; Autrey, T.; Shioyama, H.; Xu, Q. Immobilizing highly catalytically active $\mathrm{Pt}$ nanoparticles inside the pores of metal-organic framework: a double solvents approach. J. Am. Chem. Soc. 2012, 134, 13926-13929. (c) Khalily, M. A.; Eren, H.; Akbayrak, S.; Susapto, H. H.; Biyikli, N.; Özkar, S.; Guler, M. O. Facile Synthesis of Three-Dimensional $\mathrm{Pt}_{-} \mathrm{TiO}_{2}$ Nano-networks: A Highly Active Catalyst for the Hydrolytic Dehydrogenation of Ammonia-Borane. Angew. Chem., Int. Ed. 2016, 55, 12257-12261. (d) Chen, W.; Li, D.; Peng, C.; Qian, G.; Duan, X.; Chen, D.; Zhou, $\mathrm{X}$. Mechanistic and kinetic insights into the Pt-Ru synergy during hydrogen generation from ammonia borane over PtRu/CNT nanocatalysts. J. Catal. 2017, 356, 186-196. (e) Wang, X.; Liu, D.; Song, S.; Zhang, H. Synthesis of highly active $\mathrm{Pt}-\mathrm{CeO}_{2}$ hybrids with tunable secondary nanostructures for the catalytic hydrolysis of ammonia borane. Chem. Commun. 2012, 48, 10207-10209. (f) Wang, C.; Tuninetti, J.; Wang, Z.; Zhang, C.; Ciganda, R.; Salmon, L.; Moya, S.; Ruiz, J.; Astruc, D. Hydrolysis of Ammonia-Borane over Ni/ZIF-8 Nanocatalyst: High Efficiency, Mechanism, and Controlled Hydrogen Release. J. Am. Chem. Soc. 2017, 139, 11610-11615.

(7) Wang, Q.; Fu, F.; Escobar, A.; Moya, S.; Ruiz, J.; Astruc, D. Click" Dendrimer-Stabilized Nanocatalysts for Efficient Hydrogen Release upon Ammonia-Borane Hydrolysis. ChemCatChem 2018, 10, $2673-2680$.

(8) (a) Oosterom, G. E.; Reek, J. N.; Kamer, P. C.; van Leeuwen, P. W. Transition Metal Catalysis Using Functionalized Dendrimers. Angew. Chem., Int. Ed. 2001, 40, 1828-1849. (b) Astruc, D.; Boisselier, E.; Ornelas, C. Dendrimers Designed for Functions: From Physical, Photophysical and Supramolecular Properties to Applications in Sensing, Catalysis, Molecular Electronics, Photonics and Nanomedicine. Chem. Rev. 2010, 110, 1857-1959. (c) Wang, D.; Astruc, D. Dendritic catalysis. Basic concepts and recent trends. Coord. Chem. Rev. 2013, 257, 2317-2334.

(9) (a) Crooks, R. M.; Zhao, M.; Sun, L.; Chechik, V.; Yeung, L. K. Dendrimer-encapsulated metal nanoparticles: synthesis, characterization, and applications to catalysis. Acc. Chem. Res. 2001, 34, 181190. (b) Astruc, D.; Lu, F.; Aranzaes, J. R. Nanoparticles as recyclable catalysts: the frontier between homogeneous and heterogeneous catalysis. Angew. Chem., Int. Ed. 2005, 44, 7852-7872. (c) Astruc, D. Palladium Catalysis Using Dendrimers: Molecular Catalysts vs. Nanoparticles. Tetrahedron: Asymmetry 2010, 21, 1041-1054. (d) Myers, V. S.; Weir, M. G.; Carino, E. V.; Yancey, D. F.; Pande, S.; Crooks, R. M. Dendrimer-encapsulated nanoparticles: new synthesis and characterization methods and catalytic applications. Chem. Sci. 2011, 2, 1632-1646. (e) Wang, D.; Li, Y. Bimetallic Nanocrystals: Liquid-phase Synthesis and Catalytic Applications. Adv.
Mater. 2011, 23, 1044-1060. (f) Zaera, F. Nanostructured materials for applications in heterogeneous catalysis. Chem. Soc. Rev. 2013, 42, 2746-2762. (g) Deraedt, C.; Pinaud, N.; Astruc, D. Recyclable Catalytic Dendrimer Nanoreactor for Part-Per-Million $\mathrm{Cu}(\mathrm{I})$ Catalysis of "click" Reactions in Water. J. Am. Chem. Soc. 2014, 136, 12092-12098. (h) Deraedt, C.; Ye, R.; Ralston, W. T.; Toste, F. D.; Somorjai, G. A. Dendrimer-Stabilized Metal Nanoparticles as Efficient Catalysts for Reversible Dehydrogenation/Hydrogenation of Heterocycles. J. Am. Chem. Soc. 2017, 139, 18084-18092. (i) Shifrina, Z. B.; Bronstein, L. M. Magnetically Recoverable Catalysts: Beyond Magnetic Separation. Front. Chem. 2018, 6, 298.

(10) Aranishi, K.; Zhu, Q.-L.; Xu, Q. Dendrimer-Encapsulated Cobalt Nanoparticles as High-Performance Catalysts for the Hydrolysis of Ammonia Borane. ChemCatChem 2014, 6, 1375-1379.

(11) (a) Diallo, A. K.; Boisselier, E.; Liang, L.; Ruiz, J.; Astruc, D. Dendrimer-induced Molecular Catalysis in Water: the Example of Olefin Metathesis. Chem. - Eur. J. 2010, 16, 11832-11835. (b) Boisselier, E.; Diallo, A. K.; Salmon, L.; Ornelas, C.; Ruiz, J.; Astruc, D. Encapsulation and Stabilization of Gold Nanoparticles with "Click" Polyethyleneglycol Dendrimers. J. Am. Chem. Soc. 2010, 132, 2729-2742. (c) Deraedt, C.; Salmon, L.; Etienne, L.; Ruiz, J.; Astruc, D. click" dendrimers as efficient nanoreactors in aqueous solvent: $\mathrm{Pd}$ nanoparticle stabilization for sub-ppm Pd catalysis of Suzuki-Miyaura reactions of aryl bromides. Chem. Commun. 2013, 49, 8169-8171.

(12) (a) Yan, J. M.; Zhang, X.-B.; Akita, T.; Haruta, M.; Xu, Q. OneStep Seeding Growth of Magnetically Recyclable Au@Co Core-Shell Nanoparticles: Highly Efficient Catalyst for Hydrolytic Dehydrogenation of Ammonia Borane. J. Am. Chem. Soc. 2010, 132, 5326-5327. (b) Ge, Y.; Ye, W.; Shah, Z. H.; Lin, X.; Lu, R.; Zhang, S. PtNi/NiO Clusters Coated by Hollow Sillica: Novel Design for Highly Efficient Hydrogen Production from Ammonia-Borane. ACS Appl. Mater. Interfaces 2017, 9, 3749-3756. (c) Fan, G.; Li, X.; Ma, Y.; Zhang, Y.; Wu, J.; Xu, B.; Sun, T.; Gao, D.; Bi, J. Magnetic, recyclable $\mathrm{Pt}_{\mathrm{y}} \mathrm{Co}_{1-\mathrm{y}} /$ $\mathrm{Ti}_{3} \mathrm{C}_{2} \mathrm{X}_{2}(\mathrm{X}=\mathrm{O}, \mathrm{F})$ catalyst: a facile synthesis and enhanced catalytic activity for hydrogen generation from the hydrolysis of ammonia borane. New J. Chem. 2017, 41, 2793-2799. (d) Cui, X.; Li, H.; Yu, G.; Yuan, M.; Yang, J.; Xu, D.; Hou, Y.; Dong, Z. Pt coated Co nanoparticles supported on $\mathrm{N}$-doped mesoporous carbon as highly efficient, magnetically recyclable and reusable catalyst for hydrogen generation from ammonia borane. Int. J. Hydrogen Energy 2017, 42, 27055-27065. (e) Karaca, T.; Sevim, M.; Metin, Ö. Facile Synthesis of Monodisperse Copper-Platinum Alloy Nanoparticles and Their Superb Catalysis in the Hydrolytic Dehydrogenation of Ammonia Borane and Hydrazine Borane. ChemCatChem 2017, 9, 4185-4190. (f) Zhan, W.-W.; Zhu, Q.-L.; Dang, S.; Liu, Z.; Kitta, M.; Suenaga, K.; Zheng, L.-S.; Xu, Q. Synthesis of Highly Active Sub-Nanometer Pt@ $\mathrm{Rh}$ Core-Shell Nanocatalyst via a Photochemical Route: Porous Titania Nanoplates as a Superior Photoactive Support. Small 2017, 13, 1603879. (g) Ke, D.; Wang, J.; Zhang, H.; Li, Y.; Zhang, L.; Zhao, X.; Han, S. Fabrication of Pt-Co NPs supported on nanoporous graphene as high-efficient catalyst for hydrolytic dehydrogenation of ammonia borane. Int. J. Hydrogen Energy 2017, 42, 26617-26625.

(13) Fu, Z.-C.; Xu, Y.; Chan, S. L.-F.; Wang, W.-W.; Li, F.; Liang, F.; Chen, Y.; Lin, Z.-S.; Fu, W.-F.; Che, C.-M. Highly efficient hydrolysis of ammonia borane by anion $\left({ }^{-} \mathrm{OH}, \mathrm{F}^{-} \mathrm{Cl}^{-}\right)$-tuned interactions between reactant molecules and $\mathrm{CoP}$ nanoparticles. Chem. Commun. 2017, 53, 705-708.

(14) (a) Keaton, R. J.; Blacquiere, J. M.; Baker, R. T. Base Metal Catalyzed Dehydrogenation of Ammonia-Borane for Chemical Hydrogen Storage. J. Am. Chem. Soc. 2007, 129, 1844-1845. (b) Bhattacharya, P.; Krause, J. A.; Guan, H. Mechanistic Studies of Ammonia Borane Dehydrogenation Catalyzed by Iron Pincer Complexes. J. Am. Chem. Soc. 2014, 136, 11153-11161. (c) Buss, J. A.; Edouard, G. A.; Cheng, C.; Shi, J.; Agapie, T. Molybdenum Catalyzed Ammonia Borane Dehydrogenation: Oxidation State Specific Mechanisms. J. Am. Chem. Soc. 2014, 136, 11272-11275.

(15) For good CoNP catalysts in $A B$ hydrolysis, see the reviews in ref 3 and the following: (a) Umegaki, T.; Yan, J. M.; Zhang, X. B.; Shioyama, H.; Kuriyama, N.; Xu, Q. Co-SiO ${ }_{2}$ nanosphere-catalyzed 
hydrolytic dehydrogenation of ammonia borane for chemical hydrogen storage. J. Power Sources 2010, 195, 8209-8214. (b) Yan, J. M.; Zhang, X. B.; Shioyama, H.; Xu, Q. Room temperature hydrolytic dehydrogenation of ammonia borane catalyzed by Co nanoparticles. J. Power Sources 2010, 195, 1091-194. (c) Rakap, M.; Özkar, S. Hydroxyapatite-supported cobalt $(0)$ nanoclusters as efficient and cost-effective catalyst for hydrogen generation from the hydrolysis of both sodium borohydride and ammonia-borane. Catal. Today 2012, 183, 17-25. (d) Zahmakiran, M.; Özkar, S. Transition Metal Nanoparticles in Catalysis for the Hydrogen Generation from the Hydrolysis of Ammonia-Borane. Top. Catal. 2013, 56, 11711183. (e) Hu, J. T.; Chen, Z. X.; Li, M. X.; Zhou, X. H.; Lu, H. B. Amine-Capped Co Nanoparticles for Highly Efficient Dehydrogenation of Ammonia Borane. ACS Appl. Mater. Interfaces 2014, 6, 13191-13200. (f) Yang, L.; Cao, N.; Du, C.; Dai, H. M.; Hu, K.; Luo, W.; Cheng, G. Z. Graphene supported cobalt $(0)$ nanoparticles for hydrolysis of ammonia borane. Mater. Lett. 2014, 115, 113-116. (g) Wang, H. X.; Zhao, Y. R.; Cheng, F. Y.; Tao, Z. L.; Chen, J. Cobalt nanoparticles embedded in porous $\mathrm{N}$-doped carbon as longlife catalysts for hydrolysis of ammonia borane. Catal. Sci. Technol. 2016, 6, 3443-3448. (h) Zhou, L. M.; Meng, J.; Li, P.; Tao, Z. L.; Mai, L. Q.; Chen, J. Ultrasmall cobalt nanoparticles supported on nitrogen-doped porous carbon nanowires for hydrogen evolution from ammonia borane. Mater. Horiz. 2017, 4, 268-273.

(16) (a) Deraedt, C.; Astruc, D. Homeopathic" Palladium Nanoparticle Catalysis of Cross Carbon-Carbon Coupling Reaction. Acc. Chem. Res. 2014, 47, 494-503. (b) Wang, D.; Deraedt, C.; Salmon, L.; Labrugère, C.; Etienne, L.; Ruiz, J.; Astruc, D. Efficient and Magnetically Recoverable "Click" PEGylated $\gamma$ - $\mathrm{Fe}_{2} \mathrm{O}_{3}$-Pd Nanoparticle Catalysts for Suzuki-Miyaura, Sonogashira, and Heck Reactions with Positive Dendritic Effects. Chem. - Eur. J. 2015, 21, 1508-1519. (c) Wang, D.; Deraedt, C.; Ruiz, J.; Astruc, D. Magnetic and Dendritic Catalysts. Acc. Chem. Res. 2015, 48, 1871-1880. (d) Wang, C.; Ikhlef, D.; Kahlal, S.; Saillard, J.-Y.; Astruc, D. Metalcatalyzed azide-alkyne "click" reactions: Mechanistic overview and recent trends. Coord. Chem. Rev. 2016, 316, 1-20. (e) Liu, X.; Gregurec, D.; Irigoyen, J.; Martinez, A.; Moya, S.; Ciganda, R.; Hermange, P.; Ruiz, J.; Astruc, D. Precise localization of metal nanoparticles in dendrimer nanosnakes or inner periphery and consequences in catalysis. Nat. Commun. 2016, 7, 13152. (f) Wang, C.; Ciganda, R.; Salmon, L.; Gregurec, D.; Irigoyen, J.; Moya, S.; Ruiz, J.; Astruc, D. Highly Efficient Transition Metal Nanoparticle Catalysts in Aqueous Solutions. Angew. Chem., Int. Ed. 2016, 55, 3091-3095. (g) Ciganda, R.; Li, N.; Deraedt, C.; Gatard, S.; Zhao, P.; Salmon, L.; Hernandez, R.; Ruiz, J.; Astruc, D. Gold nanoparticles as electron reservoir redox catalysts for 4-nitrophenol reduction: a strong stereoelectronic ligand influence. Chem. Commun. 2014, 50, 1012610129.

(17) Stanislaus, A.; Cooper, B. H. Aromatic Hydrogenation Catalysis: A Review. Catal. Rev.: Sci. Eng. 1994, 36, 75-123.

(18) Fu, F.; Wang, C.; Wang, Q.; Martinez-Villacorta, A. M.; Escobar, A.; Chong, H.; Wang, X.; Moya, S.; Salmon, L.; Fouquet, E.; Ruiz, J.; Astruc, D. Highly Selective and Sharp Volcano-type Synergistic $\mathrm{Ni}_{2} \mathrm{Pt} @ Z I F-8-C a t a l y z e d$ Hydrogen Evolution from Ammonia Borane Hydrolysis. J. Am. Chem. Soc. 2018, 140, 1003410042.

(19) Kalidindi, S. B.; Sanyal, U.; Jagirdar, B. R. Nanostructured Cu and $\mathrm{Cu} @ \mathrm{Cu}_{2} \mathrm{O}$ core shell catalysts for hydrogen generation from ammonia-borane. Phys. Chem. Chem. Phys. 2008, 10, 5870-5874.

(20) Ma, H.; Na, C. Isokinetic Temperature and Size-Controlled Activation of Ruthenium-Catalyzed Ammonia Borane Hydrolysis. ACS Catal. 2015, 5, 1726-1735.

(21) Peng, C.-Y.; Kang, L.; Cao, S.; Chen, Y.; Lin, Z.-S.; Fu, W.-S. Nanostructured $\mathrm{Ni}_{2} \mathrm{P}$ as a Robust Catalyst for the Hydrolytic Dehydrogenation of Ammonia-Borane. Angew. Chem., Int. Ed. 2015, 54, 15725-15729.

(22) Astruc, D. Organometallic Chemisty and Catalysis; Springer: Heidelberg, Germany, 2007; pp 81-106. 